\title{
One year of GH replacement therapy with a fixed low-dose regimen improves body composition, bone mineral density and lipid profile of GH-deficient adults
}

\author{
Cesar L Boguszewski, Ludimyla H F Meister, Daniele C T Zaninelli and Rosana B Radominski \\ SEMPR, Serviço de Endocrinologia e Metabologia do Hospital de Clínicas da Universidade Federal do Paraná, Curitiba, Brazil \\ (Correspondence should be addressed to C L Boguszewski; Email: cesarluiz@hc.ufpr.br)
}

\begin{abstract}
Objective: We have studied the effects on body composition and metabolism of a fixed low dose of growth hormone (GH), $0.6 \mathrm{IU}(0.2 \mathrm{mg}) /$ day, administered for 12 months to GH-deficient (GHD) adults. Design and methods: Prospective open-label study, using 18 GHD patients (11 women, 7 men; aged 21-58 years). All investigations were performed at baseline and after 12 months. Body composition was determined by dual energy X-ray absorptiometry.

Results: Total body fat decreased $(-1.74 \pm 2.87 \%)$ and lean body mass (LBM) increased $(1.27 \pm 2.08 \mathrm{~kg})$ after therapy $(P<0.05)$. Changes in truncal fat did not reach statistical significance, but a decrease varying from 0.72 to $2.78 \mathrm{~kg}$ (1 to $8.7 \%)$ was observed in 13 (72\%) patients. Bone mineral density (BMD) increased at lumbar spine, total femur and femoral neck $(P<0.05)$. Levels of total and low-density lipoprotein (LDL)-cholesterol were lower after therapy $(P<0.05)$, and their changes were directly associated with values at baseline. Insulin levels increased and the insulin resistance index worsened at 12 months $(P<0.05)$. Median IGF-I S.D. score was -4.30 (range, -11.03 to -0.11 ) at baseline and -1.73 (range, -9.80 to 2.26 ) at 12 months. Normal ageadjusted IGF-I levels were obtained with therapy in 5 of 11 patients who had low IGF-I levels at baseline. Changes in IGF-I levels were not correlated with any biological end point, except changes in LBM $(r=0.53, P=0.02)$. Side effects were mild and disappeared spontaneously.

Conclusions: One-year of a fixed low-dose GH regimen in GHD adults resulted in a significant reduction in body fat, total cholesterol and LDL-cholesterol, and a significant increase in LBM and BMD at lumbar spine and femur, regardless of normalization of IGF-I levels. This regimen led to an elevation of insulin levels and a worsening of the insulin resistance index.
\end{abstract}

European Journal of Endocrinology 152 67-75

\section{Introduction}

Growth hormone deficiency (GHD) in adults is associated with increased total and visceral body fat, reduced bone mineral density, unfavorable lipid profile and abnormalities in glucose metabolism. Short- and longterm growth hormone $(\mathrm{GH})$ therapy in adults is aimed at improving the aberrations associated with GHD, but there are still outstanding questions concerning the optimal GH therapeutic approach to reach the goal $(1-4)$.

Initial studies of $\mathrm{GH}$ therapy in adults used high doses ( 5 IU/day) based on body weight or body surface area, which resulted in an unacceptably high frequency of side effects, mainly due to fluid retention (5-9). In subsequent studies, doses were reduced and individualized according to the patient's susceptibility to GH therapy, which is mainly influenced by age, gender and adiposity (10-12). It is currently recommended to start therapy in adults with a low dose of $\mathrm{GH}(\sim 0.45-0.9 \mathrm{IU}$ or $0.15-0.3 \mathrm{mg} /$ day $)$, with increments at monthly intervals to maintain normal insulin-like growth factor-I (IGF-I) levels, preferably within $50 \%$ to $75 \%$ of the reference range (13). This approach has been shown to improve abnormalities associated with GHD in adults, with a more gradual and less pronounced response compared with the high-dose regimens used in the past, and with a lower incidence of side effects $(10,13-15)$.

Although normal IGF-I is the target of GH therapy, many GHD adults have normal IGF-I at the time of diagnosis $(1,13)$. In addition, significant changes in body composition and lipid abnormalities have been reported after 3 months of low GH dose in GHD adults, even in those patients who maintained subnormal serum IGF-I levels (16). Some findings have suggested that continuous treatment with $\mathrm{GH}$ may be associated with increased sensitivity to the hormone.

Cathecholamine-induced and GH-induced lipolysis of fat cells derived from GHD adults were more pronounced after 6 months of GH therapy in comparison with values obtained when cells were first exposed 
to GH in vitro (17). Therefore, if it is true that the biological response to GH may increase with time and positive effects of GH therapy might occur even in patients with subnormal IGF-I levels, then a fixed low replacement dose of $\mathrm{GH}$ could progressively promote beneficial therapeutic outcomes, offering a cost-effective approach to the treatment of some adults with GHD.

This open-label protocol was, therefore, designed to investigate whether and how a low dose regimen of $\mathrm{GH}(0.6 \mathrm{IU}$ or $0.2 \mathrm{mg} /$ day), fixed during 1 year regardless of IGF-I levels, may affect body composition and metabolic indices in adult patients with GHD.

\section{Subjects and methods}

\section{Patients}

Eighteen subjects (11 women and 7 men; median age, 41.5 years; range, $21-58$ years), with a diagnosis of GHD confirmed by a peak serum GH response of less than $3 \mu \mathrm{g} / \mathrm{l}$ during insulin-induced hypoglycemia (ITT), were studied. Four patients had childhood-onset GHD (idiopathic, craniopharyngioma, Pit-1 deficiency and empty sela) and 14 had adult-onset GHD (5 patients due to Sheehan's syndrome, 2 patients due to craniopharyngioma, 2 patients due to prolactinoma, 2 patients due to non-functioning pituitary adenoma, 1 patient due to germinoma, 1 patient due to trauma and 1 patient after treatment for acromegaly). Full anterior pituitary gland failure was present in 14 patients ( 3 with diabetes insipidus), while 2 patients had thyrotropin (TSH) and luteinizing hormone/follicle-stimulating hormone deficiencies associated with GHD, 1 had TSH and adrenocorticotropin deficiencies and 1 had only TSH deficiency. Patients were treated with conventional substitution therapy when indicated. Some women of menopausal age were not receiving sex steroids due to individual preferences. None of the patients had received GH therapy preceding inclusion in the study. Informed consent was obtained from all subjects, and the study was approved by the Ethics Committee for Research in Human Beings of our University Hospital.

\section{Study design}

All patients were treated with daily s.c. injections of recombinant human GH (Norditropin, Novo Nordisk Farmaceutica Ltd, Sao Paulo, Brazil) given at bedtime for 12 months. The dose of $0.6 \mathrm{IU} /$ day $(0.2 \mathrm{mg} /$ day $)$ was maintained during the whole period of the study. There were no specific recommendations regarding diet or physical activities for the patients. At enrolment, clinical examination (including anthropometric parameters), biochemical and hormonal profile, muscular strength, body composition and bone mineral density (BMD) were evaluated in all patients. Fasting blood samples were drawn at $0800-0900 \mathrm{~h}$ for measurements. The patients were followed after 1, 3,
6, 9 and 12 months of GH therapy, and at each visit they were asked about clinical improvements and sideeffects. All investigations were repeated after 12 months of therapy. Insulin resistance (IR) was clinically estimated before and after GH therapy by the homeostasis model assessment (HOMA), according to the equation: $\quad$ HOMA-IR=insulin $\quad(\mu \mathrm{U} / \mathrm{ml}) \times$ glycemia $(\mathrm{mmol} / \mathrm{l}) / 22.5(18)$.

\section{Assays}

Serum IGF-I was measured by immunoradiometric assay (Diagnostic Systems Laboratories, Inc., Webster, TX, USA). The sensitivity of the assay was $0.8 \mu \mathrm{g} / \mathrm{l}$. The intra- and interassay coefficients of variation were, according to the manufacturer, $3.4 \%$ and $9.6 \%$ respectively. Age-adjusted values for IGF-I were used according to the manufacturer's information. We have calculated standard deviation scores (SDS) for serum levels of IGF-I, which refer to the number of S.D. differences from the age-related normal mean value. A score between -2 S.D. and +2 S.D. is considered as a normal value. The IGF-I SDS was calculated according to the following formulae (16):

$$
\begin{aligned}
\text { Men, } 18- & 28 \text { years: } \\
\text { IGF-I SDS }= & ((\log (\text { IGF-I })-3.59686+0.07981 \\
& \left.\times \text { age }-0.001212 \times(\text { age })^{2}\right) / \\
& (0.24928-0.01419 \times \text { age }+0.0003595 \\
& \left.\left.\times(\text { age })^{2}\right)\right)
\end{aligned}
$$

Women, 18-28 years:

IGF-I SDS $=((\log ($ IGF-I $)-3.64235+0.08376$

$$
\begin{aligned}
& \left.\times \text { age }-0.001294 \times(\text { age })^{2}\right) / \\
& (0.21944-0.01178 \times \text { age }+0.0003119 \\
& \left.\left.\times(\text { age })^{2}\right)\right)
\end{aligned}
$$

Men and women, 29-70 years:

$$
\begin{aligned}
\text { IGF-I SDS }= & ((\log (\text { IGF-I })-2.36031+0.002393 \\
& \times \text { age }) /(0.137825+0.0001846 \times \text { age }))
\end{aligned}
$$

Measurements of glucose, insulin, total cholesterol, triglyceride, and high-density lipoprotein (HDL)-cholesterol were analyzed by routine methods in our laboratory. Low-density lipoprotein (LDL)-cholesterol concentrations were estimated according to the formula published by Friedewald et al. (19) .

\section{Body composition}

Body mass index (BMI) was calculated as weight divided by the square of height $\left(\mathrm{kg} / \mathrm{m}^{2}\right)$. Waist circumference 
was evaluated between the lowest rib margin and the iliac crest by the same investigator, using a $0.5 \mathrm{~cm}$ width inelastic meter and considering the mean value of two measurements. Total body fat, truncal fat and total lean body mass (LBM) were studied by dual-energy X-ray absorptiometry (DXA) using equipment from Lunar Radiation Corp. (Madison, WI, USA). The interassay coefficient of variation for body composition by DXA in our laboratory was $1 \%$.

\section{Bone mineral density}

BMD, expressed as milligrams per $\mathrm{cm}^{2}$, was measured by DXA using equipment from Lunar Radiation Corp. BMD was performed in lumbar spine, total femur and femoral neck. The interassay coefficients of variation were $1.2 \%, 1.2 \%$ and $1.5 \%$ for lumbar spine, total femur and femoral neck respectively.

\section{Muscular strength}

Muscular strength was examined at four sites: right hand, left hand, subescapular muscles and dorsal muscles, by the use of specific dinamometers (Takei, Fit Systems, Inc., Calgary, Canada). The hand strength test was performed three times for each hand and the tests were performed twice at the other sites, with an interval of $1 \mathrm{~min}$ between the examinations. The best score reached by the patient in each strength test was used for analysis. The same procedure was performed in a control group of healthy volunteers (12 women and six men; median age, 37 years (range, 26-58 years); median BMI, $22.3 \mathrm{~kg} / \mathrm{m}^{2}$ (range, $\left.17.6-31.2 \mathrm{~kg} / \mathrm{m}^{2}\right)$ ).

\section{Statistical analysis}

Results are expressed as the mean \pm S.D. of values, unless otherwise stated. Comparisons between parameters at study start and at 12 months were made by Student's paired $t$-test when the values showed a normal pattern of distribution, or by Wilcoxon's Signed Rank Test when there was a high degree of non-normality in the distribution. Simple regression analyses were performed to investigate linear relationships between study parameters, and Pearson's correlation coefficient was used to calculate correlations. Differences were considered statistically significant at values of $P<0.05$.

\section{Results \\ GH dose}

Considering the weight of patients, the fixed dose of $0.6 \mathrm{IU}(0.2 \mathrm{mg}) \mathrm{GH}$ used in this study resulted in a mean $\mathrm{GH}$ dose of $0.003 \mathrm{mg} / \mathrm{kg} /$ day $(3 \mu \mathrm{g} / \mathrm{kg} /$ day $)$.

\section{Effects of GH therapy on body composition and muscular strength}

BMI did not change, whereas waist circumference was reduced with $\mathrm{GH}$ therapy $(-1.84 \pm 3.31 \mathrm{~cm}$; $P=0.03$ ) (Table 1). Total body fat decreased significantly after GH therapy in the whole group $(-1.74 \pm 2.87 \% ; P=0.01)$ (Fig. 1). Changes in truncal fat did not reach statistical significance. However, reduction of truncal fat varying from 0.72 to $2.78 \mathrm{~kg}$ (1 to $8.7 \%$ ) was observed after $\mathrm{GH}$ therapy in 13 $(72 \%)$ of our patients. LBM increased significantly with GH therapy $(1.27 \pm 2.08 \mathrm{~kg} ; P=0.01)$ (Table 1 , Fig. 1). At baseline, GHD women had lower muscular strength compared with healthy women in the right hand (13.4 \pm 4.2 kilogram force (kgf) vs $25.3 \pm 4.8 \mathrm{kgf} ; P=0.0001)$, left hand $(15.0 \pm 6.3 \mathrm{kgf}$ vs $24.7 \pm 4.0 \mathrm{kgf} ; P=0.02)$ and subescapular muscles $(13.7 \pm 4.4 \mathrm{kgf}$ vs $19.3 \pm 3.9 \mathrm{kgf} ; P=0.01)$, but not in dorsal muscles $(42.7 \pm 23.8 \mathrm{kgf}$ vs $56.6 \pm 16.9 \mathrm{kgf}$; $P=$ not significant). Muscular strength of GHD men did not differ from that in the controls at any of the four sites examined (right hand: $36.5 \pm 17.1 \mathrm{kgf}$ vs $28.4 \pm 11.3 \mathrm{kgf}$; left hand: $36.7 \pm 14.8 \mathrm{kgf}$ vs $30.4 \pm 8.1 \mathrm{kgf} ;$ subescapular muscles: $33.4 \pm 10.8 \mathrm{kgf}$ vs $24.6 \pm 6.2 \mathrm{kgf}$; dorsal muscles: $108.3 \pm 30.9 \mathrm{kgf}$ vs $101.0 \pm 25.3 \mathrm{kgf}$ ). The low dose of GH had no significant effect on muscular strength in GHD women and men (Table 1).

\section{Effects of GH therapy on bone}

At study entry, BMD at femoral neck was significantly greater in GHD men than in women $\left(1.027 \pm 0.19 \mathrm{~g} / \mathrm{cm}^{2}\right.$ vs $\left.0.807 \pm 0.07 \mathrm{~g} / \mathrm{cm}^{2} ; P<0.01\right)$, but no differences were observed at lumbar spine and at total femur. BMD increased significantly after $\mathrm{GH}$ therapy at lumbar spine $\left(1.131 \pm 0.21 \mathrm{~g} / \mathrm{cm}^{2}\right.$ vs $1.121 \pm 0.21 \mathrm{~g} / \mathrm{cm}^{2}$ at baseline; $\left.P=0.009\right)$, at total femur $\left(0.968 \pm 0.16 \mathrm{~g} / \mathrm{cm}^{2}\right.$ vs $0.900 \pm 0.13 \mathrm{~g} / \mathrm{cm}^{2}$ at baseline; $P=0.001)$ and femoral neck $(0.948 \pm$ $0.18 \mathrm{~g} / \mathrm{cm}^{2}$ vs $0.903 \pm 0.17 \mathrm{~g} / \mathrm{cm}^{2}$ at baseline; $P=$ 0.04) (Table 1, Fig. 2). Gender differences in response to the therapy were found, with only women demonstrating a significant increment in BMD at lumbar spine $\left(1.054 \pm 0.18 \mathrm{~g} / \mathrm{cm}^{2}\right.$ vs $1.022 \pm 0.18 \mathrm{~g} / \mathrm{cm}^{2}$ at baseline; $P=0.02)$ and at total femur $\left(0.922 \pm 0.11 \mathrm{~g} / \mathrm{cm}^{2}\right.$ vs $0.864 \pm 0.08 \mathrm{~g} / \mathrm{cm}^{2}$ at baseline; $\left.P=0.006\right)$.

\section{Effects of GH therapy on glucose homeostasis, serum lipoproteins and thyroid function}

Plasma glucose levels did not change after 12 months of GH therapy. However, HOMA-IR worsened with therapy $(3.14 \pm 2.3$ vs $1.93 \pm 1.0$ at baseline; $P=0.02)$ due to elevations in insulin levels $(15.3 \pm 12.1 \mu \mathrm{IU} / \mathrm{ml}$ vs $9.7 \pm 4.2 \mu \mathrm{IU} / \mathrm{ml}$ at baseline; $P=0.05$ ) (Fig. 3). HDLcholesterol and triglyceride did not change significantly with therapy, while a significant reduction in total 
Table 1 Clinical and biochemical features of growth hormone-deficient (GHD) patients at baseline and after 12 months of therapy with a fixed low-dose regimen of $\mathrm{GH}(0.6 \mathrm{IU}$ or $0.2 \mathrm{mg} /$ day $)$.

\begin{tabular}{|c|c|c|c|c|c|c|}
\hline & \multicolumn{3}{|c|}{ Baseline } & \multicolumn{3}{|c|}{12 months } \\
\hline & All $(n=18)$ & Women $(n=11)$ & Men $(n=7)$ & All $(n=18)$ & Women $(n=11)$ & Men $(n=7)$ \\
\hline Age (years) & $40.6 \pm 11.2$ & $41.4 \pm 11.3$ & $39.2 \pm 11.7$ & & & \\
\hline $\mathrm{BMI}\left(\mathrm{kg} / \mathrm{m}^{2}\right)$ & $28.2 \pm 4.6$ & $28.5 \pm 5.2$ & $27.6 \pm 4.0$ & $28.1 \pm 4.4$ & $28.6 \pm 4.8$ & $27.3 \pm 3.7$ \\
\hline Waist $(\mathrm{cm})^{\prime}$ & $94.9 \pm 10.9$ & $92.6 \pm 10.8$ & $98.4 \pm 10.7$ & $93.0 \pm 10.3^{b}$ & $90.4 \pm 10.0$ & $97.1 \pm 10.2$ \\
\hline Total body fat (kg) & $23.5 \pm 7.2$ & $25.5 \pm 6.0$ & $20.2 \pm 8.2$ & $21.9 \pm 7.0^{\mathrm{b}}$ & $24.3 \pm 5.6$ & $18.0 \pm 7.7$ \\
\hline Total body fat (\%) & $34.2 \pm 10.3$ & $40.3 \pm 6.9$ & $24.7 \pm 7.1^{\mathrm{a}}$ & $32.3 \pm 10.1^{b}$ & $38.8 \pm 5.6^{b}$ & $22.1 \pm 6.1$ \\
\hline Truncal fat $(\mathrm{kg})$ & $11.8 \pm 3.3$ & $12.6 \pm 2.9$ & $10.4 \pm 3.7$ & $11.3 \pm 3.1$ & $12.4 \pm 2.3$ & $9.5 \pm 3.4$ \\
\hline Truncal fat $(\%)$ & $36.1 \pm 9.9$ & $41.8 \pm 7.1$ & $27.2 \pm 6.4^{\mathrm{a}}$ & $34.5 \pm 9.4$ & $40.7 \pm 5.0$ & $24.7 \pm 5.0$ \\
\hline Lean body mass $(\mathrm{kg})$ & $44.3 \pm 15.5$ & $35.4 \pm 8.4$ & $58.3 \pm 14.0^{\mathrm{a}}$ & $45.6 \pm 15.5^{b}$ & $36.3 \pm 7.5$ & $60.3 \pm 13.3$ \\
\hline Lumbar spine $\left(\mathrm{g} / \mathrm{cm}^{2}\right)$ & $1.121 \pm 0.21$ & $1.022 \pm 0.18$ & $1.263 \pm 0.19$ & $1.131 \pm 0.21^{\mathrm{b}}$ & $1.054 \pm 0.18^{\mathrm{b}}$ & $1.259 \pm 0.20$ \\
\hline Total femur $\left(\mathrm{g} / \mathrm{cm}^{2}\right)$ & $0.900 \pm 0.13$ & $0.864 \pm 0.08$ & $0.965 \pm 0.19$ & $0.968 \pm 0.16^{\mathrm{b}}$ & $0.922 \pm 0.11^{\mathrm{b}}$ & $1.045 \pm 0.21$ \\
\hline Femoral neck $\left(\mathrm{g} / \mathrm{cm}^{2}\right)$ & $0.903 \pm 0.17$ & $0.807 \pm 0.07$ & $1.027 \pm 0.19^{a}$ & $0.948 \pm 0.18^{b}$ & $0.906 \pm 0.16$ & $1.018 \pm 0.20$ \\
\hline \multicolumn{7}{|l|}{ Muscular strength } \\
\hline Right hand (kgf) & $23.0 \pm 15.9$ & $13.3 \pm 4.2$ & $36.5 \pm 17.1$ & $25.8 \pm 14.8$ & $17.3 \pm 8.6$ & $38.0 \pm 13.5$ \\
\hline Left hand (kgf) & $23.4 \pm 14.8$ & $15.0 \pm 6.3$ & $36.7 \pm 14.8$ & $25.2 \pm 14.3$ & $16.4 \pm 8.5$ & $39.0 \pm 10.1$ \\
\hline Subescapular (kgf) & $21.3 \pm 12.2$ & $13.7 \pm 4.4$ & $33.4 \pm 10.8$ & $22.3 \pm 14.0$ & $13.5 \pm 6.3$ & $36.3 \pm 11.0$ \\
\hline Dorsal (kgf) & $64.5 \pm 40.1$ & $42.7 \pm 23.8$ & $108.3 \pm 30.9$ & $68.0 \pm 35.6$ & $47.4 \pm 23.0$ & $105.1 \pm 17.1$ \\
\hline IGF-I (ng/ml) & $76.9 \pm 70.4$ & $61.3 \pm 60.2$ & $101.3 \pm 82.9$ & $133.7 \pm 134.1$ & $123.1 \pm 106.6$ & $153.3 \pm 184.7$ \\
\hline IGF-I SDS & $-4.53 \pm 3.74$ & $-5.19 \pm 3.94$ & $-3.49 \pm 3.43$ & $-3.10 \pm 4.19$ & $-3.22 \pm 4.29$ & $-2.88 \pm 4.36$ \\
\hline Glucose $(\mathrm{mmol} / \mathrm{l})$ & $4.51 \pm 0.5$ & $4.62 \pm 0.4$ & $4.34 \pm 0.6$ & $4.69 \pm 0.6$ & $4.65 \pm 0.6$ & $4.75 \pm 0.7$ \\
\hline Insulin $(\mu \mathrm{lU} / \mathrm{ml})$ & $9.7 \pm 4.2$ & $10.8 \pm 4.6$ & $7.9 \pm 2.7$ & $15.3 \pm 12.1^{c}$ & $17.9 \pm 13.6^{\mathrm{c}}$ & $9.5 \pm 5.2$ \\
\hline HOMA-ÏR & $1.93 \pm 1.0$ & $2.20 \pm 1.1$ & $1.50 \pm 0.6$ & $3.14 \pm 2.3^{\mathrm{b}}$ & $3.63 \pm 2.6^{\mathrm{b}}$ & $2.06 \pm 1.1$ \\
\hline Cholesterol $(\mathrm{mmol} / \mathrm{l})$ & $5.78 \pm 1.1$ & $5.70 \pm 0.9$ & $5.90 \pm 1.5$ & $5.21 \pm 1.2$ & $5.40 \pm 1.0$ & $4.83 \pm 1.5$ \\
\hline $\mathrm{HDL}(\mathrm{mmol} / \mathrm{l})$ & $1.14 \pm 0.2$ & $1.20 \pm 0.2$ & $1.06 \pm 0.2$ & $1.20 \pm 0.2$ & $1.22 \pm 0.3$ & $1.14 \pm 0.1$ \\
\hline $\mathrm{LDL}(\mathrm{mmol} / \mathrm{l})$ & $4.04 \pm 1.1$ & $4.00 \pm 1.1$ & $4.11 \pm 1.2$ & $3.29 \pm 1.1^{\mathrm{b}}$ & $3.58 \pm 0.8$ & $2.78 \pm 1.3^{b}$ \\
\hline Triglycerides $(\mathrm{mmol} / \mathrm{l})$ & $2.00 \pm 1.2$ & $1.89 \pm 0.8$ & $2.17 \pm 1.8$ & $1.51 \pm 0.6$ & $1.66 \pm 0.6$ & $1.24 \pm 0.5$ \\
\hline Free $T_{4}(n g / d l)$ & $1.17 \pm 0.4$ & $1.29 \pm 0.4$ & $0.97 \pm 0.3$ & $1.2 \pm 0.3$ & $1.1 \pm 0.3$ & $1.2 \pm 0.4$ \\
\hline Total $\mathrm{T}_{4}(\mu \mathrm{g} / \mathrm{dl})$ & $9.6 \pm 2.5$ & $10.2 \pm 2.5$ & $7.9 \pm 1.6$ & $8.6 \pm 2.4$ & $8.7 \pm 2.5$ & $9.4 \pm 2.2$ \\
\hline Total $\mathrm{T}_{3}(\mathrm{ng} / \mathrm{dl})$ & $103.3 \pm 18.4$ & $106.7 \pm 20.6$ & $99.2 \pm 14.5$ & $103.8 \pm 24.7$ & $105.5 \pm 27.3$ & $101.4 \pm 22.4$ \\
\hline
\end{tabular}

${ }^{\mathrm{a}} P<0.05$ men vs women; ${ }^{\mathrm{b}} P<0.05$ vs baseline; ${ }^{\mathrm{c}} P=0.05$ vs baseline.

$\mathrm{T}_{4}$, thyroxine; $\mathrm{T}_{3}$, tri-iodothyronine.

cholesterol $(5.78 \pm 1.1 \mathrm{mmol} / \mathrm{l}$ vs $5.21 \pm 1.2 \mathrm{mmol} / \mathrm{l}$; $P=0.03)$ and LDL-cholesterol $(4.04 \pm 1.1 \mathrm{mmol} / \mathrm{l}$ vs $3.29 \pm 1.1 \mathrm{mmol} / \mathrm{l} ; \quad P=0.004$ ) was noted (Table 1 , Fig. 3). Percentual changes in total cholesterol and LDL-cholesterol during therapy were correlated with basal levels of cholesterol $(r=0.69 ; P=0.003)$ and LDL-cholesterol $(r=0.75 ; P=0.001)$. In men, percentual change in triglyceride with therapy was correlated to basal triglyceride levels $(r=0.91 ; \quad P=0.02)$. Thyroid function tests were normal in all patients at study entry and no significant changes occurred with GH therapy.

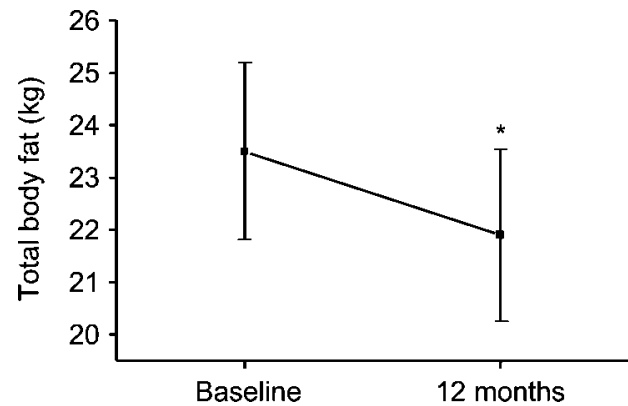

\section{Effects of GH therapy on serum IGF-I levels and IGF-I SDS}

At baseline, mean IGF-I levels were $76.9 \pm 70.4 \mathrm{ng} / \mathrm{ml}$ (median: $42.5 \mathrm{ng} / \mathrm{ml}$; range: 4.8 to $212.8 \mathrm{ng} / \mathrm{ml}$ ) and mean IGF-I SDS was $-4.53 \pm 3.74$ (median: -4.3 ; range: -11.03 to -0.11 ). Age-adjusted IGF-I levels were in the normal range in seven patients $(35 \%$; three men and four women) and low in 11 patients (65\%; four men and seven women). After 12 months of the low-dose regimen of GH, mean IGF-I levels were $133.7 \pm 134.1 \mathrm{ng} / \mathrm{ml}$ (median: $140.8 \mathrm{ng} / \mathrm{ml}$; range: 7.2

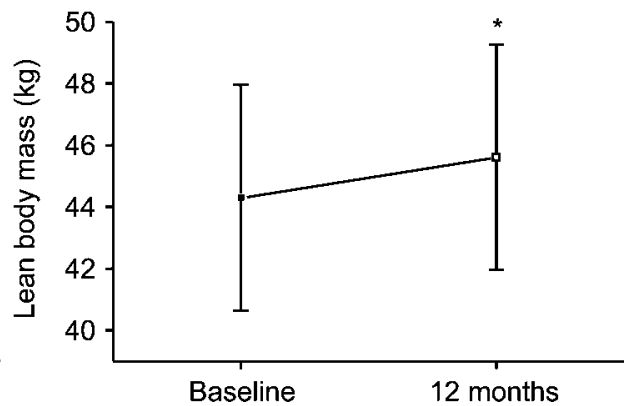

Figure 1 Effect of a fixed low dose of GH replacement therapy ( $0.6 \mathrm{IU}$ or $0.2 \mathrm{mg} / \mathrm{day})$ for 12 months on total body fat and lean body mass in $18 \mathrm{GH}$-deficient adults. Horizontal bars indicate \pm S.E.M. for the mean value shown. ${ }^{*} P<0.05$. 

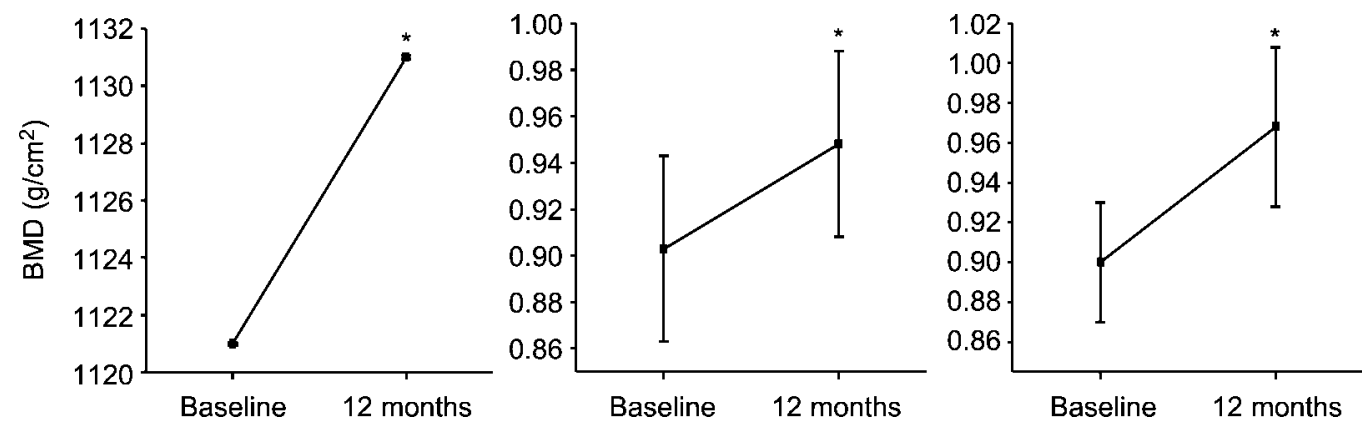

Figure 2 Effect of a fixed low dose of GH replacement therapy ( $0.6 \mathrm{IU}$ or $0.2 \mathrm{mg} / \mathrm{day})$ for 12 months on bone mineral density (BMD) at lumbar spine, femoral neck and total femur in $18 \mathrm{GH}$-deficient adults. Horizontal bars indicate \pm S.E.M. for the mean value shown. ${ }^{*} P<0.05$.

to $506.4 \mathrm{ng} / \mathrm{ml}$ ) and IGF-I SDS were $-3.10 \pm 4.19$ (median: -1.73 ; range: -9.8 to 2.26 ). Normalization of age-adjusted levels of IGF-I was obtained with therapy in five of 11 patients (two men and three women) who had low IGF-I levels at baseline. IGF-I SDS were subnormal (below -2 SDS) in 10 patients (three men and seven women) at baseline, with five (two men and three women) achieving normal values at 12 months (Fig. 4).

\section{Correlations between changes in IGF-I levels, body composition and metabolic parameters}

There was a significant positive correlation between changes in LBM and changes in IGF-I levels $(r=0.53$,
$P=0.02)$, whereas a negative correlation between changes in LBM and truncal fat $(r=-0.48, P=0.04)$ was found. In GHD women, changes in total body fat, truncal fat and LBM during GH therapy were associated with the correspondent values at baseline (total body fat: $r=0.69, P=0.01$; truncal fat: $r=0.74, P=0.008$; LBM: $r=-0.66, P=0.02$ ). There were no correlations between changes in IGF-I and IGF-I SDS and those of glucose, insulin, HOMA-IR and lipoproteins.

\section{Side effects}

Two GHD women reported side effects. One patient with a diagnosis of hypopituitarism due to Pit-1 mutation
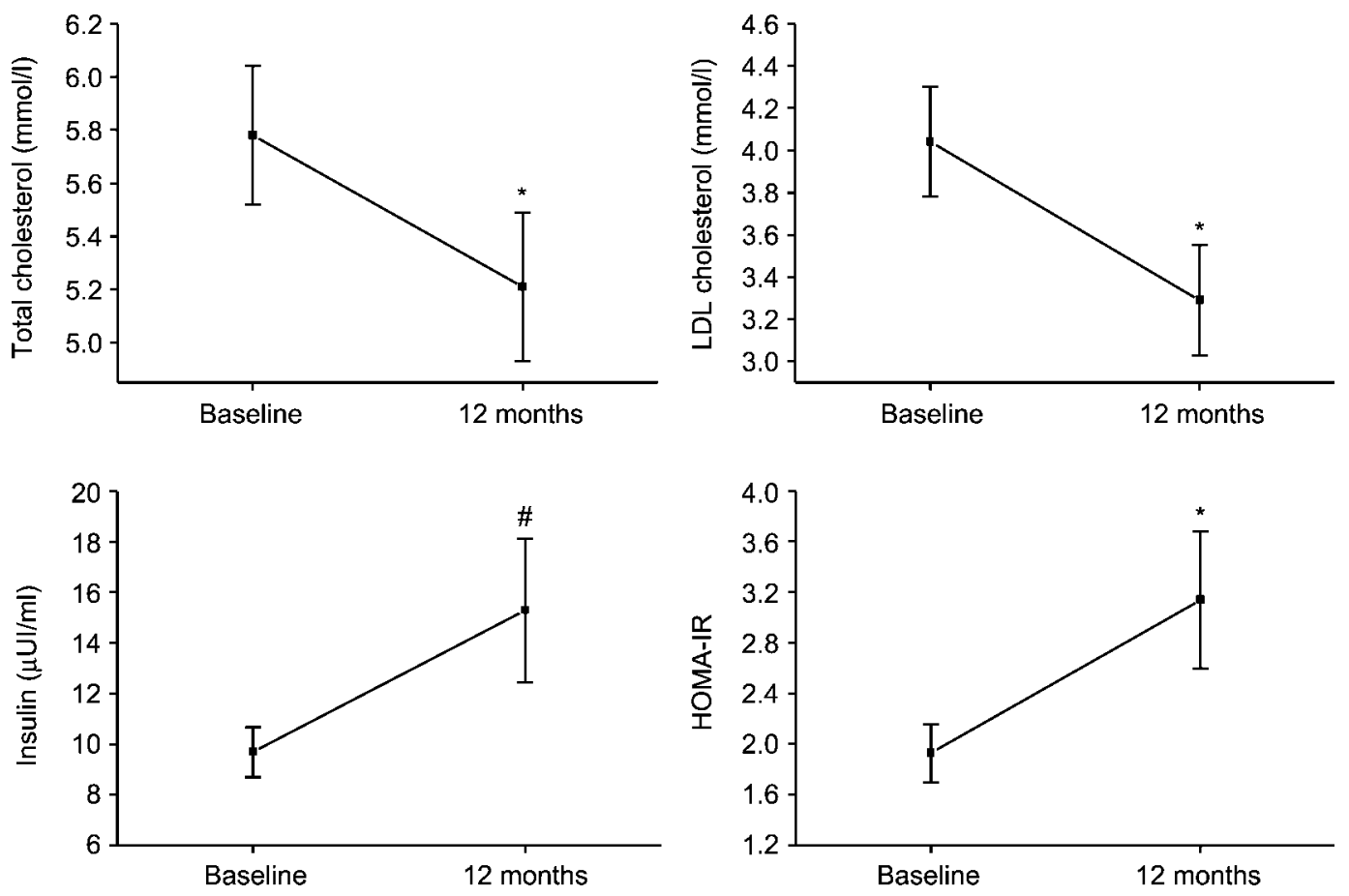

Figure 3 Effect of a fixed low dose of GH replacement therapy ( $0.6 \mathrm{IU}$ or $0.2 \mathrm{mg} /$ day) for 12 months on serum total cholesterol, low density lipoprotein (LDL)-cholesterol, insulin and homeostasis model assessment of insulin resistance (HOMA-IR) in $18 \mathrm{GH}$-deficient adults. Horizontal bars indicate \pm S.E.M. for the mean value shown. ${ }^{*} P<0.05,{ }^{\#} P=0.05$. 


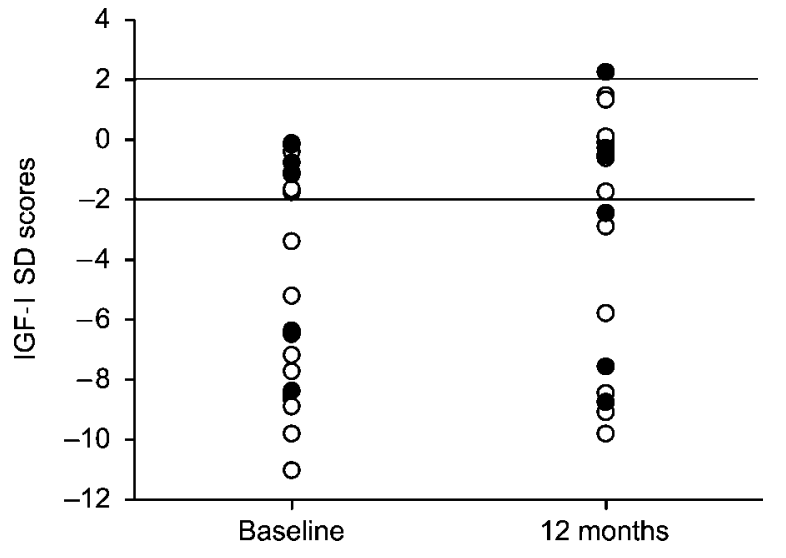

Figure 4 Effect of a fixed low dose of growth hormone (GH) replacement therapy ( $0.6 \mathrm{IU}$ or $0.2 \mathrm{mg} /$ day) for 12 months on insulin-like growth factor (IGF)-I standard deviation scores (SD scores) in $18 \mathrm{GH}$-deficient adults. Horizontal bars indicate normal range between -2 and +2 SD scores. Open circles represent GHD women and solid circles represent GHD men.

developed arthralgia and edema, and another patient with congenital hypopituitarism complained of edema. Both patients had low IGF-I SDS at baseline and after 12 months, and their symptoms disappeared after approximately 2 weeks without modification of the dose. No patient discontinued the treatment or had to reduce the dose due to serious adverse events.

\section{Discussion}

In this open-label study, we have shown that a fixed low dose of $0.6 \mathrm{IU}(0.2 \mathrm{mg}) \mathrm{GH}$ per day administered for 12 months to GHD adults was able to promote significant changes in body composition, lipid profile and insulin levels, even in patients who did not achieve normal IGF-I levels. Side effects with this regimen were mild and recovered spontaneously, with no need for dose adjustment. Despite the fact that this was not a placebo-controlled trial and some of the effects could be due to life-style modifications, the observed changes were all in agreement with the previously described results in placebo-controlled and open-label studies of $\mathrm{GH}$ replacement in adults.

Several reports have demonstrated that optimal GH doses for replacement in adults are significantly lower than the weight-based doses used in the past. A recent large multinational study has confirmed that an individualized regimen using a gradually increasing dose of GH and careful monitoring of serum IGF-I levels has similar efficacy and is better tolerated than a fixed body weight-based regimen (20). These observations are in line with the lower daily production of $\mathrm{GH}$ in adults, which is influenced by several factors such as age, gender and adiposity $(21,22)$. Considering the availability of s.c. injection of $\mathrm{GH}$, it has been suggested that the mean physiological dose in middleaged GHD patients should be between 0.3-0.9 IU $(0.1-0.3 \mathrm{mg})$ per day, higher in women than in men
(23). In our study, we have chosen the mid-dose of $0.6 \mathrm{IU}(0.2 \mathrm{mg})$ for both men and women, which is similar or very close to the starting replacement dose used in most recently published clinical studies. Using this dose for 12 weeks, Janssen et al. (23) found that serum IGF-I levels increased into the normal range in GHD men, but not in women. In our group, the same dose used for 12 months resulted in normal ageadjusted IGF-I levels and normal IGF-I SDS in 3 out of 7 women and in 2 out of 4 men who had low IGF-I and low IGF-I SDS at study entry.

Although IGF-I has been used for monitoring GH replacement in GHD adults, its serum concentrations may not always reflect GH status $(24,25)$. Ezzat et al. (26) have found in a group of GHD adults that the effects of GH on lipoproteins, cardiac function, and quality of life could not be predicted by changes in IGF-I levels, which were only associated with alterations in LBM, in line with the findings of our study. In a short-term study with a low GH dose $(0.5 \mathrm{IU}$ or $0.17 \mathrm{mg} /$ day), Gillberg et al. (16) have shown marked biological effects despite the fact that IGF-I levels did not normalize in many of their patients. Moreover, changes in serum IGF-I could not predict the shortterm responsiveness of metabolic end-points in their study. Consequently, it seems possible to obtain positive effects of GH therapy in GHD adults even in the presence of subnormal IGF-I levels. In the present study, we have demonstrated, for the first time, that longterm therapy with a fixed low dose of GH in GHD adults is able to promote significant improvements in body composition, bone mineral density and lipid profile, regardless of normalization of IGF-I levels. Despite these positive effects, it should be borne in mind that abnormalities associated with GHD were not totally corrected with this regimen and that a state of relative GHD in some patients might still be associated with higher morbidity and mortality risk.

The GH replacement regimen used in our study led to a significant increase in LBM and a decrease in body fat measured by DXA. In published series of GHD adults, GH therapy has resulted in a mean body fat reduction of $4-6 \mathrm{~kg}$ and a mean LBM increase of $2.0-5.5 \mathrm{~kg}$ (1), in comparison with $1.6 \mathrm{~kg}$ and $1.3 \mathrm{~kg}$ respectively observed in our patients. As expected, the fixed low dose of GH promoted changes in body composition of a lesser magnitude than those found with high doses, but the response was highly variable among patients, as seen with other regimens. Nevertheless, abnormalities of body composition do not seem to be good markers of GH efficacy, as increments in the GH dose in an attempt to normalize body composition have been shown to result in over-treatment $(4,10)$. Adults with GHD demonstrate unfavorable fat mass distribution, with increased amounts of abdominal fat, but the effects of GH therapy on fat compartments have not been consistently reported in the studies $(1-4)$. In our study group, changes in truncal fat did not 
reach statistical significance, but two-thirds of our patients had a beneficial reduction of truncal fat varying from 0.72 to $2.78 \mathrm{~kg}$ ( 1 to $8.7 \%$ ), with an associated reduction in waist circumference.

An important aspect of our study was that a fixed low dose of $0.6 \mathrm{IU}(0.2 \mathrm{mg}) \mathrm{GH}$ markedly improved $\mathrm{BMD}$ at lumbar spine and femur. Our findings are in line with the idea that a low $\mathrm{GH}$ dose seems optimal for restoring bone mass in GHD adults, as it avoids the initial decline in BMD frequently observed when higher doses are used $(1,4,27,28)$. GH is a stimulator of both bone resorption and bone formation (29), and a low dose of GH may generate a more marked anabolic action than higher doses, as low IGF-I stimulates bone formation more markedly than bone resorption (30, 31). Abrahamsen et al. (28) have demonstrated that $0.004 \mathrm{mg} / \mathrm{kg} /$ day of $\mathrm{GH}$ stimulated bone remodeling and increased BMD over 12 months in GHD patients, irrespective of gender, while a higher dose of $0.015 \mathrm{mg} / \mathrm{kg} /$ day was associated with initial declines in forearm and whole-body BMD in their patients. In our study, a mean dose of $0.003 \mathrm{mg} / \mathrm{kg} /$ day of $\mathrm{GH}$ resulted in more pronounced changes on BMD in GHD women than in men.

Lipid and lipoprotein abnormalities have been well documented in adults with GHD $(1-4,32)$. In this study, no significant changes were observed on HDLcholesterol and triglyceride levels, but total cholesterol and LDL-cholesterol levels were reduced significantly with fixed low dose GH therapy. In addition, the greatest changes in total cholesterol and LDL-cholesterol have occurred in patients with the highest levels at baseline. This is in line with several studies in adults with GHD showing that the degree of improvement in most biological end points is proportional to the degree of deviation from normal at baseline (14).

Most placebo-controlled and open trials lasting at least 12 months have not found significant effects of GH therapy on HDL-cholesterol and triglyceride levels, whereas reductions in total and LDL-cholesterol have been the most consistent findings during $\mathrm{GH}$ replacement therapy $(1,32)$. These results might be explained by the relative hyperinsulinemia induced by $\mathrm{GH}$ and the availability of free fatty acids, resulting in an increased hepatic very low-density lipoprotein (VLDL) secretion (32). In fact, significant elevation of insulin levels and worsening of insulin resistance, as clinically evaluated by HOMA, were the only negative effects observed in our patients, which might be related to a disproportionate reduction of fat mass in relation to the hyperinsulinemia induced by the low dose $\mathrm{GH}$ regimen. It is likely that long-term beneficial effects of GH therapy on body composition may overcome its negative influence on glucose metabolism (33). Yuen et al. (34) have recently compared a group of 13 GHD adults who received a fixed low dose of $\mathrm{GH}$ $(0.1 \mathrm{mg} /$ day $)$ over 12 months with a group of 12
GHD adults who were conventionally treated with the titrating standard regimen. In contrast with our findings, they found enhanced insulin sensitivity without changes in body composition in patients treated with a fixed low dose, whereas the group treated with the titrating regimen showed a marked decrease in total fat mass with no modifications of insulin sensitivity. In their study, the fixed $\mathrm{GH}$ dose administered was half that which we gave to our patients, which may partly explain the divergent results found on body composition and insulin sensitivity.

The recombinant $\mathrm{GH}$ used in therapy has sequence homology with endogenous human GH, which suggests that the resulting side effects almost exclusively occurred as a consequence of an excessive replacement dose (35). Relevant adverse events resulted in a dose reduction in up to $40 \%$ of patients in the first trials using high $\mathrm{GH}$ doses based on body weight $(1,35)$. Consequently, smaller doses have been employed, which have been implicated with more gradual effects and less adverse events over time (20). Our fixed low dose $\mathrm{GH}$ replacement therapy was safe, with only three mild side effects reported, peripheral edema and arthralgia in one patient and edema in another one, which disappeared after approximately 2 weeks, with no need for dose adjustment.

In summary, this open-label study has shown that one year of fixed low dose $\mathrm{GH}$ administration results in reduced body fat, total cholesterol and LDL-cholesterol, increased LBM and BMD at lumbar spine and femur, and elevated insulin levels and insulin resistance. These effects, except for LBM, were not correlated with IGF-I changes and occurred independently of achieving normal serum IGF-I levels.

\section{Acknowledgements}

Recombinant GH (Norditropin) was generously supplied by Novo Nordisk Farmaceutica do Brasil Ltd (Sao Paulo, Brazil). We would like to thank Dr Victor Fernando Lopez Arce, Gislaine Custodio Piovezan, Flavia Shibata and Carolina Ferraz da Silva for technical support.

\section{References}

1 Simpson H, Savine R, Sonksen P, Bengtsson BA, Carlsson L, Christiansen JS, Clemmons D, Cohen P, Hintz R, Ho K, Mullis P, Robinson I, Strasburger C, Tanaka T \& Thorner M GRS Council Growth hormone replacement therapy for adults: into the new millennium. Growth Hormone and IGF Research 2002 12 1-33.

2 Bengtsson B-Å, Johannsson G, Shalet SM, Simpson H \& Sönksen PH. Treatment of growth hormone deficiency in adults. Journal of Clinical Endocrinology and Metabolism 200085 933-942.

3 Frohman LA. Controversy about treatment of growth hormonedeficient adults: a commentary. Annals of Internal Medicine 2002 $137202-204$. 
4 Gaillard R-C \& Giusti V. Dosing and individual responsiveness to growth hormone replacement therapy. In Growth Hormone Deficiency in Adults: 10 Years of KIMS, edn 1, ch. 10, pp 103-116. Eds R Abs \& U Feldt-Rasmussen. Oxford: Oxford Pharmagenesis Ltd, 2004.

5 Salomon F, Cuneo RC, Hesp R \& Sönksen PH. The effects of treatment with recombinant human growth hormone on body composition and metabolism in adults with growth hormone deficiency. New England Journal of Medicine 1989321 1797-1803.

6 Jorgensen JO, Pedersen SA, Thuesen L, Jorgensen J, IngemannHansen T, Skakkebaek NE \& Christiansen JS. Benefical effects of growth hormone treatment in GH-deficient adults. Lancet 1989 1 1221-1225.

7 Binnerts A, Swart GR, Wilson JH, Hoogerbrugge N, Pols HA, Birkenhager JC \& Lamberts SW. The effect of growth hormone administration in growth hormone-deficient adults on bone, protein, carbohydrate and lipid homeostasis, as well as body composition. Clinical Endocrinology 199237 79-87.

8 Whitehead HM, Boreham C, McIlrath EM, Sheridan B, Kennedy L, Atkinson AB \& Hadden DR. Growth hormone treatment of adults with growth hormone deficiency: results of a 13-month placebo controlled crossover study. Clinical Endocrinology $1992 \mathbf{3 6}$ 45-52.

9 Bengtsson B-Å, Eden S, Lonn L, Kvist H, Stokland A, Lindstedt G, Bosaeus I, Tolli J, Sjostrom L \& Isaksson OG. Treatment of adults with growth hormone $(\mathrm{GH})$ deficiency with recombinant human GH. Journal of Clinical Endocrinology and Metabolism $1993 \mathbf{7 6}$ 309-317.

10 Johannsson G, Rosén $\mathrm{T}$ \& Bengtsson B-Å. Individualized dose titration of growth hormone $(\mathrm{GH})$ during $\mathrm{GH}$ replacement in hypopituitary adults. Clinical Endocrinology $1997 \mathbf{4 7}$ $571-581$.

11 Drake WM, Coyte D, Camacho-Hubner C, Jivanji NM, Kaltsas G, Wood DF, Trainer PJ, Grossman AB, Besser GM \& Monson JP. Optimizing growth hormone replacement therapy by dose titration in hypopituitary adults. Journal of Clinical Endocrinology and Metabolism $1998 \mathbf{8 3} 3913-3919$.

12 Murray RD, Skillicorn CJ, Howell SJ, Lissett CA, Rahim A \& Shalet SM. Dose titration and patient selection increases the efficacy of GH replacement in severely GH-deficient adults. Clinical Endocrinology 199950 749-757.

13 Growth Hormone Research Society. Consensus guidelines for the diagnosis and treatment of adults with growth hormone deficiency: summary statement of the Growth Hormone Research Society workshop on adult growth hormone deficiency. Journal of Clinical Endocrinology and Metabolism $1998 \mathbf{8 3} 379-381$.

14 Murray RD \& Shalet SM. Adult growth hormone replacement lessons learned and future directions. Journal of Clinical Endocrinology and Metabolism 200287 4427-4428.

15 Moller J, Jorgensen JO, Laursen T, Frystyk J, Naeraa RW, Orskov H \& Christiansen JS. Growth hormone dose regimens in adult $\mathrm{GH}$ deficiency: effects on biochemical growth markers and metabolic parameters. Clinical Endocrinology 199339 403-408.

16 Gillberg P, Bramnert M, Thoren M, Werner S \& Johannsson G. Commencing growth hormone replacement in adults with a fixed low dose. Effects on serum lipoproteins, glucose metabolism, body composition, and cardiovascular function. Growth Hormone and IGF Research 2001 11 273-281.

17 Harant I, Beauville M, Crampes F, Riviere D, Tauber MT, Tauber JP \& Garrigues M. Response of fat cells to growth hormone $(\mathrm{GH})$ : effect of long term treatment with recombinant human $\mathrm{GH}$ in GH-deficient adults. Journal of Clinical Endocrinology and Metabolism 199478 1392-1395.

18 Matthews DR, Hosker JP, Rudenski AS, Naylor BA, Treacher DF \& Turner RC. Homeostasis model assessment: insulin resistance and beta-cell function from fasting plasma glucose and insulin concentrations in man. Diabetologia $1985 \mathbf{2 8}$ 412-419.
19 Friedewald WT, Levy RI \& Fredrickson DS. Estimation of the concentration of low-density lipoprotein cholesterol in plasma, without use of the preparative ultracentrifuge. Clinical Chemistry 197218 499-502.

20 Hoffman AR, Strasburger CJ, Zagar A, Blum WF, Kehely A \& Hartman ML. Efficacy and tolerability of an individualized dosing regimen for adult growth hormone replacement therapy in comparison with fixed body weight-based dosing. Journal of Clinical Endocrinology and Metabolism $2004 \mathbf{8 9}$ 3224-3233.

21 Veldhuis JD, Liem AY, South S, Weltman A, Weltman J, Clemmons DA, Abbott R, Mulligan T, Johnson ML, Pincus S, Straume M \& Iranmanesh A. Differential impact of age, sex steroid hormones, and obesity on basal versus pulsatile growth hormone secretion in men as assessed in an ultrasensitive chemiluminescence assay. Journal of Clinical Endocrinology and Metabolism $1995 \mathbf{8 0}$ 3209-3222.

22 van den Berg G, Veldhuis JD, Frolich M \& Roelfsema F. An amplitude-specific divergence in the pulsatile mode of growth hormone $(\mathrm{GH})$ secretion underlies the gender difference in mean GH concentrations in men and premenopausal women. Journal of Clinical Endocrinology and Metabolism $1996 \mathbf{8 1}$ 2460-2467.

23 Janssen YJH, Frölich M \& Roelfsema F. A low starting dose of genotropin in growth hormone-deficient adults. Journal of Clinical Endocrinology and Metabolism 199782 129-135.

24 Mukherjee A, Monson JP, Jonsson PJ, Trainer PJ, Shalet SM \& KIMS International Board. Seeking the optimal target range for insulin-like growth factor I during the treatment of adult growth hormone disorders. Journal of Clinical Endocrinology and Metabolism $2003 \mathbf{8 8} 5865-5870$.

25 Hoffman DM, O'Sullivan AJ, Baxter RC \& Ho KK. Diagnosis of growth hormone deficiency in adults. Lancet $1994 \mathbf{3 4 3}$ 1064-1068.

26 Ezzat S, Fear S, Gaillard RC, Gayle C, Marcovitz S, Mattioni T, Nussey S, Rees A \& Svanberg E. Circulating IGF-I levels in monitoring and predicting efficacy during long-term GH treatment of GH-deficient adults. European Journal of Endocrinology 2003149 499-509

27 Holmes SJ, Whitehouse RW, Swindell R, Economou G, Adams JE \& Shalet SM. Effect of growth hormone replacement on bone mass in adults with adult onset growth hormone deficiency. Clinical Endocrinology $1995 \mathbf{4 2} 627-633$.

28 Abrahamsen B, Hangaard J, Horn HC, Hansen TB, Gregersen G, Hansen-Nord M, Vahl N, Junker P, Andersen M \& Hagen C. Evaluation of the optimum dose of growth hormone $(\mathrm{GH})$ for restoring bone mass in adult-onset $\mathrm{GH}$ deficiency: results from two 12month randomized studies. Clinical Endocrinology $20025 \mathbf{5 7}$ 273-281.

29 Bravenboer N, Holzmann P, de Boer H, Roos JC, van der Veen EA $\&$ Lips P. The effect of growth hormone $(\mathrm{GH})$ on histomorphometric indices of bone structure and bone turnover in GH-deficient men. Journal of Clinical Endocrinology and Metabolism $1997821818-1822$.

30 Ghiron LJ, Thompson JL, Holloway L, Hintz RL, Butterfield GE, Hoffman AR \& Marcus R. Effects of recombinant insulin-like growth factor-I and growth hormone on bone turnover in elderly women. Journal of Bone and Mineral Research 199510 $1844-1852$.

31 Amato G, Izzo G, La Montagna G \& Bellastella A. Low dose recombinant human growth hormone normalizes bone metabolism and cortical bone density and improves trabecular bone density in growth hormone-deficient adults without causing adverse effects. Clinical Endocrinology $1996 \mathbf{4 5} 27-32$.

32 Abrams P \& Abs R. The lipid profile in adult hypopituitary patients with growth hormone deficiency. In Growth Hormone Deficiency in Adults: 10 Years of KIMS, edn 1, ch. 12, pp 127-138. Eds R Abs \& U Feldt-Rasmussen. Oxford: Oxford Pharmagenesis Ltd, 2004. 
33 Giavoli C, Porretti S, Ronchi CL, Cappiello V, Ferrante E, Orsi E, Arosio M \& Beck-Peccoz P. Long-term monitoring of insulin sensitivity in growth hormone-deficient adults on substitutive recombinant human growth hormone therapy. Metabolism $200453740-743$.

34 Yuen KCJ, White DK, Chatterjee KK, Harris PE, Fryklund L, Murgotroyd PR \& Dunger DB. Improved insulin sensitivity and quality of life without alterations in body composition in $\mathrm{GH}$-deficient adults following 12 months of fixed low dose $\mathrm{GH}$ administration. Proceedings of the 84th Endocrine Society Annual Meeting, New Orleans, pp 82, 2004 OR9-5.

35 de Boer H \& van der Veen E. Guidelines for optimizing growth hormone replacement therapy in adults. Hormone Research $19974821-30$.

Received 9 June 2004

Accepted 6 October 2004 